\title{
Management of Ectopic Pregnancy in a Tertiary Care Hospital by Surgery
}

\author{
SAIDAAKTER ${ }^{1}$, SHARMIN SULTANA $^{2}$
}

\begin{abstract}
Introduction: Tubal ectopics if large, uncontrollably bleeding or severely damaged need radical surgery (salpingectomy), otherwise conservative surgery (salpingotomy, salpingostomy) is the way of operative management. Laparoscopic surgery usually done in case of haemodynamically stable condition.

Objective: To explore the different ways of surgical management of ectopic pregnancy in a tertiary care hospital.

Materials and methods: This cross sectional study was carried out in the Department of Obstetrics and Gynaecology, Shaheed Suhrawardy Hospital and Dhaka Medical College Hospital during August 2005 and June 2006. The study population consisted of 50 women with ectopic pregnancy. Selected women underwent meticulous history taking and physical examinations. Some investigations like ultrasonography, culdocentesis, urine for pregnancy tests were done. Patients were treated by either radical or conservative surgery.

Results: All (100\%) women had abdominal tenderness. Ectopic pregnancy was diagnosed by history, physical examination and culdocentesis (84\%), ultrasonography (12\%) and laparotomy (4\%). Two (4\%) women were treated by conservative surgery, while the rest by radical surgery; 40 (80\%) underwent unilateral salpingectomy, 3 (6\%) unilateral salpingectomy with contralateral tubectomy, 2 (4\%) unilateral salpingo oophorectomy, 1 (2\%) total abdominal hysterectomy and 2 (4\%) resection of rudimentary horn.
\end{abstract}

Conclusion: Most common diagnostic tools were by history, physical examination and culdocentesis and common management was unilateral salpingectomy.

Key words: Ectopic pregnancy, Diagnosis, Management

\section{Introduction:}

Ectopic gestations are pregnancies resulting from misimplantation of the blastocyst, in an aberrant area that is usually not conductive to further development and growth (anywhere else apart from the endometrial lining of uterine cavity). It not only leads to fetal wastage, but also increases the incidence of maternal morbidity, mortality and problems of future fertility ${ }^{1}$.

Site of ectopic pregnancies are (a) tubal pregnancy $95 \%$, includes ampullary $55 \%$, isthmic $25 \%$, fimbrial $17 \%$ and interstitial $2 \%$, and (b) others $5 \%$, includes cervical, ovarian and abdominal. But most abdominal pregnancies are from tubal abortion or rupture and subsequent implantation in the bowel, omentum or mesentry ${ }^{2}$.
The classic triad of symptoms of ectopic pregnancy are amenorrhoea, abdominal pain and appearance of vaginal bleeding. Feeling of nausea, vomiting, fainting attacks, even to the extent of syncope, may be present $^{3}$. Breen in his series showed $85 \%$ patients presenting with history of amenorrhoea ${ }^{4}$. Ratnam reported in this series $75.9 \%$ who presented with cervical movement tenderness ${ }^{5}$.

Early detection of ectopic pregnancy before rupture presents a diagnostic challenge. Lawson showed $76 \%$ cases positive on ultrasonography with false negative result in 33\% cases, colpoopuncture was positive in $82.18 \%$ cases $^{6}$.

An accurate history taking and proper physical examination are considered to be most important in

1. Saida Akter, Assistant Professor, Ad din Medical College Hospital, 2 Bara Maghbazar, Dhaka 1217

2. Sharmin Sultana, Medical Officer, 200 Bedded Hospital, Narayanganj 
the diagnosis of ectopic pregnancy. It is well known that the diagnosis of ectopic pregnancy is difficult as the patient may present with varied clinical picture. The mode of presentation and clinical features are sometimes confusing, and there is often considerable delays before the diagnosis can be made with confidence ${ }^{7}$.

As soon as the diagnosis is made, immediate operative treatment is essential because the priority is to treat ruptured ectopic pregnancy which is life threatening to the mother. Though many of the unruptured tubal pregnancy, as well as ruptured tubal pregnancy, may be managed by laparoscopic technique, very early unruptured tubal pregnancy, as well as some chronic tubal pregnancy, have been treated with systemic methotrexate ${ }^{8}$.

Advantages of medical treatment are: (a) significant reduction of operative morbidity, hospital stay, as well as cost, and (b) improved chance of subsequent successful pregnancy may be a potential benefit.

Conservative surgical measure includes milking of the tube, linear salpingotomy, linear salpingostomy which may be carried out by cautery or laser and segmental resection ${ }^{9}$.

To preserve the maternal life and future fertility of the patient, high index of suspicion, early and accurate diagnosis, immediate and skillful surgery and moral responsibility remain the cornerstone of management of ectopic pregnancy.

In this study, we tried to find out best possible surgical ways of management of ectopic pregnancy cases in a tertiary care hospital.

\section{Materials and methods:}

This cross sectional study was carried out in the Department of Obstetrics and Gynaecology, Shaheed Suhrawardy Hospital and Dhaka Medical College Hospital during August 2005 and June 2006. The study population consisted of 50 women with ectopic pregnancy. Inclusion criteria was short period of amenorrhoea; pregnancy related symptoms; lower abdominal pain; vaginal bleeding; syncopal attack; on general examination, tachycardia, variable amount of anaemia and features of shock, and on vaginal examination, closed cervix and cervical motion tenderness was positive with tender adnexal mass, uterus slightly larger and softer than normal. Exclusion criteria was history of lower abdominal pain associated with (a) Low grade fever, anorexia, nausea/vomiting and increased white blood cells (favours appendicitis), (b) dysuria, increased frequency and urgency of micturition (favours cystitis), and (c) spiking fever/chills with increased frequency and urgency of micturition (favours urinary tract infection).

On admission, all selected women underwent meticulous history taking and physical examinations. Some investigations like ultrasonography, culdocentesis, urine for pregnancy test were done.

All collected information were recorded in predesigned data collection sheet for each individual patient. Collected data were compiled and appropriate statistical analysis was done using computer based software, Statistical Package for Social Science (SPSS).

\section{Results:}

Table I characteristics of the study population. Most of the women belonged to age group 2630 years (42\%), followed by 2125 years (30\%), >30 years $(20 \%)$ and $£ 20$ years (8\%). Ten (20\%) women were primigravida and the rest $40(80 \%)$ multigravida. All 50 (100\%) women presented with abdominal pain; in order of frequency, other presenting features were period of amenorrhoea (80\%), shock (50\%), per vaginal bleeding (40\%), syncopal attack (30\%) and early pregnancy symptoms (24\%). Duration of amenorrhoea $(n=40)$ was 68 weeks $(75 \%)$ and $>8$ weeks $(25 \%)$. Character of pain was severe in $35(70 \%)$ and mild to moderate in $15(30 \%)$ cases.

Table-I

Characteristics of the study subjects $(n=50)$

\begin{tabular}{lcc}
\hline Parameters & Number of patients & Percentage \\
\hline Age (years) & 4 & \\
$\quad \leq 20$ & 15 & 8.0 \\
2125 & 21 & 30.0 \\
2630 & 19 & 42.0 \\
$>30$ & & 20.0 \\
Gravidity & 10 & 20.0 \\
$\quad$ Primi & 40 & 80.0 \\
$\quad$ Multi & & \\
Presenting symptoms & 50 & 100.0 \\
$\quad$ Abdominal pain & 40 & 80.0 \\
Period of amenorrhoea & 25 & 50.0 \\
$\quad$ Shock & 20 & 40.0 \\
$\quad$ Per vaginal bleeding & 15 & 30.0 \\
$\quad$ Syncope attack & 12 & 24.0 \\
$\quad$ Early pregnancy symptoms & & \\
Amenorrhoea (n=40) & & 75.0 \\
$\quad$ 8 weeks & 30 & 25.0 \\
$\quad>8$ weeks & 10 & 70.0 \\
Character of pain & & 30.0 \\
$\quad$ Severe \\
$\quad$ Mild to moderate & 35 & \\
\hline
\end{tabular}


Table II shows predisposing factors for ectopic pregnancy. Most common predisposing factors were pelvic inflammatory disease (PID) in 26 (52\%), followed by abortion/MR in 17 (34\%), IUCD in 7 (14\%), history of lower abdominal surgery in $4(8 \%)$, subfertility in 3 (6\%), history of tuberculosis in $2(4 \%)$ and history of ectopic pregnancy in $1(2 \%)$ cases.

Table-II

Predisposing factors

\begin{tabular}{lcc}
\hline Variables & Number of patients & Percentage \\
\hline PID & 26 & 52.0 \\
Abortion/MR & 17 & 34.0 \\
IUCD & 7 & 14.0 \\
Lower abdominal surgery & 4 & 8.0 \\
Infertility & 3 & 6.0 \\
Tuberculosis & 2 & 4.0 \\
Ectopic pregnancy & 1 & 2.0 \\
\hline
\end{tabular}

Signs and symptoms of ectopic pregnancy were abdominal tenderness in all $50(100 \%)$, pain on movement of cervix in 46 (92\%), abdominal rigidity in $38(76 \%)$, muscle guard in $32(64 \%)$, bulky uterus in 26 (52\%), abdominal mass in $7(14 \%)$ and rebound tenderness in 6 (12\%) women (Table III).

Table-III

Signs and symptoms of ectopic pregnancy

\begin{tabular}{|c|c|c|}
\hline Variables & er of patients & Percentage \\
\hline Abdominal tenderness & 50 & 100.0 \\
\hline Pain on movement of cervix & 46 & 92.0 \\
\hline Abdominal rigidity & 38 & 76.0 \\
\hline Muscle guard & 32 & 64.0 \\
\hline Bulky uterus & 26 & 52.0 \\
\hline Abdominal mass & 7 & 14.0 \\
\hline Rebound tenderness & 6 & 12.0 \\
\hline
\end{tabular}

Table IV shows diagnostic aid applied and findings. In case of 42 (84\%) women, diagnosis was made by history taking, physical examination and culdocentesis, in case of $6(12 \%)$ women by ultrasonography and in case of $2(4 \%)$ women by laparotomy.

Table IV

Diagnostic parameters of ectopic pregnancy $(n=50)$

Variables Number of patients Percentage

\begin{tabular}{lll}
\hline History, physical & 42 & 84.0
\end{tabular}

examination

and culdocentesis

\begin{tabular}{lcc} 
Ultrasonography & 6 & 12.0 \\
Laparotomy & 2 & 4.0 \\
\hline
\end{tabular}

Table $\mathrm{V}$ shows diagnostic finding. Site of ectopic pregnancy were tubal (90\%), cornual (6\%) and ovarian (4\%). Of the 45 tubal pregnancy, right side was involved in 25 (55.6\%) and left side in 20 (44.4\%) cases; and condition of fallopian was ruptured in 43 (95.6\%) and unruptured in 2 (4.4\%) women.

Table-V

Findings of ectopic pregnancy $(n=50)$

\begin{tabular}{lcc}
\hline Variables & Number of patients & Percentage \\
\hline Site of ectopic pregnancy & 45 & \\
Tubal & 3 & 90.0 \\
Cornual & 2 & 6.0 \\
Ovarian & 4.0 \\
Tubal pregnancy side involved $(\mathrm{n}=45)$ & \\
Right & 25 & 55.6 \\
Left & 20 & 44.4 \\
Condition of fallopian tube $(\mathrm{n}=45)$ & \\
Ruptured & 43 & 95.6 \\
Unruptured & 2 & 4.4 \\
\hline
\end{tabular}

Table VI shows type of management of ectopic pregnancy. Out of 50 cases, conservative surgical treatment was given to 2 (4\%) women. Radical surgical treatment, such as unilateral sulpingectomy was required in case of $40(80 \%)$, unilateral salpingectomy with contralateral tubectomy in $3(6 \%)$, unilateral salpingo oophorectomy in $2(4 \%)$, total abdominal hysterectomy in $1(2 \%)$ and resection of rudimentary horn in 2 (4) cases.

Table-VI

Management of ectopic pregnancy $(n=50)$

\begin{tabular}{lcc}
\hline Variables & $\begin{array}{c}\text { Number of } \\
\text { patients }\end{array}$ & Percentage \\
\hline $\begin{array}{l}\text { Unilateral salpingectomy } \\
\text { Unilateral salpingectomy } \\
\text { with contralateral } \\
\text { tubectomy }\end{array}$ & 40 & 80.0 \\
$\begin{array}{l}\text { Unilateral salpingo } \\
\text { oophorectomy }\end{array}$ & 3 & 6.0 \\
$\begin{array}{l}\text { Resection of rudimentary } \\
\text { horn }\end{array}$ & 2 & 4.0 \\
$\begin{array}{l}\text { Total abdominal } \\
\text { hysterectomy } \\
\text { Conservative surgical }\end{array}$ & 1 & 4.0 \\
treatment & 2 & 4.0 \\
\hline
\end{tabular}




\section{Discussion:}

In the present study, $42 \%$ women belonged to age group 2630 years, 30\% to 2125 years, $20 \%$ to $>30$ years and $8 \%$ to $£ 20$ years. Fernandes et al. found that $65 \%$ patients belonged to age group 2535 years and $6 \%$ were adolescents ${ }^{10}$. Studies done in Bangladesh showed age incidence as 46\% (26 30 years) by Nahar, as $38 \%$ ( 2630 years) in a study by Zabin, and as $45 \%$ (25 34 years) by Siddiqua et al. ${ }^{11,13}$.

In this study, most of the women were multigravid (80\%), only $20 \%$ were primigravid. This is consistent with other studies, where the proportion of ectopic in primigravida was $38 \%$ and $23.8 \% 11,13$.

General symptoms as presented by the patients included the classical triad of pain $(100 \%)$, amenorrhoea (80\%), per vaginal bleeding (40\%), along with shock (50\%), syncopal attack (30\%) and early pregnancy symptoms (24\%). In a study by Nahar, it was abdominal pain (100\%), amenorrhoea (70\%), per vaginal bleeding (50\%) and early pregnancy symptoms $(24 \%)^{11}$. In a study by Zabin, it was abdominal pain (100\%), amenorrhoea (78\%), per vaginal bleeding $(60 \%)$ and early pregnancy symptoms $(48 \%)^{12}$. Tancer et al. in their study found that patients presented with abdominal pain (90\%), abnormal vaginal discharge (63.8\%) and early pregnancy symptoms $(23.4 \%)^{14}$. Siddiqua et al. found that their patients presented with abdominal pain (95\%), amenorrhoea (65\%) and per vaginal bleeding $(7 \%)^{13}$. Amenorrhoea of 68 weeks was present in $75 \%(n=40)$ women, while it was found $50 \%$ in a study by Nahar, $56 \%$ by Zabin and $61 \%$ by Siddiqua et al ${ }^{11,13}$.

Out of predisposing factors, pelvic inflammatory disease (PID) was present in 26 (52\%) women of the present series, which is higher than the studies by Nahar (24\%), Zabin (48\%) and Smith (24\%) ${ }^{11,12,15}$. History of induced abortion increases the risk of ectopic pregnancy 14 fold $^{16}$. This study showed that 17 (34\%) women presented with history of abortion/MR, which is lower than the studies by Nahar (42\%) and Zabin $(48 \%)^{11,12}$. History of IUCD use was observed in 7 (14\%) cases of the present study compared to $16 \%$ by Nahar and $34 \%$ by Zabin ${ }^{11,12}$. In the present study, 3 women (6\%) presented with history of infertility/ subfertility, which is very low compared to the studies by Nahar (22\%) and Siddiqua (28\%) ${ }^{11,13}$.

In the present study, signs and symptoms of ectopic pregnancy were abdominal tenderness (100\%), pain on movement of cervix (92\%), abdominal rigidity (76\%), muscle guard (64\%), bulky uterus (52\%), abdominal mass (14\%) and rebound tenderness (12\%). In similar studies, Nahar observed abdominal tenderness in $100 \%$ cases, Zabin in $100 \%$ cases and Tancer et al. in $90.8 \%$ cases $^{11,12,14}$. Pain on movement of cervix was observed in $90 \%$ cases by Nahar and in 51\% cases by Tuomivaara et al. ${ }^{11,17}$.

In the present study, history, physical examination and culdocentesis could detect ectopic pregnancy in $42(84 \%)$ cases, ultrasound in $6(12 \%)$ cases and laparotomy in $2(4 \%)$ cases. Ultrasound findings varied widely in different studies, $24 \%$ in a study by Nahar and $92 \%$ in a study by Zabin ${ }^{11,12}$. The wide variation may be due to acute and subacute condition of the patients who required immediate laparotomy before any ultrasonography test.

Present study showed that site of ectopic pregnancy was tubal in $45(90 \%)$ cases, cornual in $3(6 \%)$ and ovarian in $2(4 \%)$. In a study by Nahar, the sites of ectopic pregnancy were ampullary (50\%), isthmic (20\%), fimbrial (10\%), rudimentary horn of bicornuate uterus (6\%), interstitial (8\%) and abdominal $(2 \%)^{11}$. In a study by Bouyer et al., the sites of ectopic pregnancy were ampullary (70\%), isthmic (12\%), fimbrial (11\%), ovarian (3\%), interstitial (2\%) and abdominal $(1 \%)^{18}$. In a study by Siddiqua et al., the sites were ampullary (64\%), isthmic (19\%), fimbrial $(12 \%)$, rudimentary horn of bicornuate uterus $(2 \%)$ and cornual $(0.67 \%)^{13}$.

Right side of the fallopian tube was affected more commonly (55.6\%) than the left (44.4\%) in the present study. In the studies by Nahar and Zabin, the right side involvement was more common (54 and 79\%, respectively) $)^{11,12}$.

Condition of fallopian tube on operation was found ruptured in $95.6 \%$ cases of the present study. However, in a study by Nahar it was $84 \%$, by Siddiqua it was $74 \% 11,13$. In studies by Broslovsky, it was $59.1 \%$ and by Muller et al., it was $44 \% 19,20$.

Unilateral salpingectomy was common in the present study (80\%), unilateral salpingo oophorectomy with contralateral tubectomy was done in $6 \%$ cases, unilateral salpingo oophorectomy in $4 \%$ cases, resection of rudimentary horn in $4 \%$ cases, total abdominal hysterectomy in $2 \%$ cases and conservative surgical treatment in $4 \%$ cases. In a study by Nahar, unilateral salpingectomy was done in $58 \%$ cases, by 
Zabin in $52 \%$ cases and by Siddiqua et al. in $71 \%$ cases $^{11} 13$.

\section{Conclusion:}

Most common diagnostic tools were history taking, physical examination and culdocentesis and common surgical management was unilateral salpingectomy.

\section{References:}

1. Cunningham, McDonald, Gant, Leveno, Gilstrap. Ectopic pregnancy. In: Williams obstetrics. 20th ed. Appleton and Lange, 1997: 60735.

2. DeCherney AH, Nathan L. Current obstetrics and gynecology, diagnosis and treatment. 9th ed. New York: McGraw Hill Book Companies, 2003: 27487.

3. Dutta DC. Textbook of obstetrics, including perinatology and contraceptives. 6th ed. Calcutta: New Central BookAgency, 2005: 179 93.

4. Breen JL. A 21 year survey of 654 ectopic pregnancies. Am J Obstet Gynecol 1970; 106:1004.

5. Ratnam SS, Rao KB, Arulkumaran S. Ectopic pregnancy. In: Obstetrics and gynaecology for postgraduates. Orient Longman, 1994: 394407.

6. Nederlof KP, Lawson HW, Saftlas AF, Atrash HK, Finch EL. Ectopic pregnancy surveillance, United States, 1970 1978. MMWR 1990; 39:9.

7. Khan T. Ectopic pregnancy: a diagnostic problem. Bangladesh J Obstet Gynaecol 1989; $4: 128$.

8. Marti LP, Sera HG. Early pregnancy risks. In: DeCherney AH, Nathan L, editors. Current obstetrics and gynaecology, diagnosis and treatment. 9th ed. 2003: 2823.

9. Drife JS. Tubal pregnancy: rising incidence, early diagnosis, more conservative treatment. $\mathrm{Br}$ Med J 1990; 301:1058 9.

10. Fernandes AM, Ribeiro LP, Morases FH, Meira PC, de Sollero CA, Yamada EM. Prevalence of ectopic pregnancy liable to surgical treatment in a public hospital from 1995 through 2000. Rev Assoc Med Bras 2005; 50:413 6.

11. Nahar K. Study on clinical presentations, management and operative findings of ectopic pregnancy [dissertation]. Dhaka: Bangladesh College of Physicians and Surgeons, 2006.

1. Zabin F. Clinical presentation, management and operative findings of ectopic pregnancy [dissertation]. Dhaka: Bangladesh College of Physicians and Surgeons, 1998.

13. Siddiqua S, Alam MM, Khan MAT. Ectopic pregnancy: a diagnostic dilemma. Bangladesh J Obstet Gynaecol 2004; 19:7 10.

14. Tancer ML, Delke I, Veridiano NP. A fifteen year experience with ectopic pregnancy. Surg Gynaecol Obstet 1981; 152:1979 82.

15. Smith JF. Ectopic pregnancy. Med Library 2005; 16.

16. Anornu RI, Oluwole A, Abudo OO, Adebajo S. Risk factors for ectopic pregnancy in Lagos, Nigeria. Acta Obstet Gynecol Scand 2005; 84:184 8.

17. Tuomivara L, Kanppila A, Puolakka I. Ectopic pregnancy: an analysis of the etiology, diagnosis and treatment in 552 cases. Arch Gynecol 1986; 237:135.

18. Bouyer J, Coste J, Fernandez H, Pouly JL, Job Spira N. Sites of ectopic pregnancy: a 10year population based study of 1800 cases. Hum Reproduc 2002; 17:3224 30.

19. Broslovsky BP. The role of laparoscopy in the diagnosis of ectopic pregnancy: a plea for conservative management. Int J Gynaecol Obstet 1984; 22:307 9.

20. Muller JE, Hacker I, Terinde R, Kozlowski P. Change in the diagnosis and therapy of extrauterine pregnancy on special emphasis of ultrasound. Study at Gynecologic Clinic of the Dusseldorf University, Gebartshilfe Frauinheilkd 1986; 2217. 